\title{
MODELAGEM GEOESTATÍSTICA 3D DA IMPEDÂNCIA ACÚSTICA PARA A CARACTERIZAÇÃO DO CAMPO DE NAMORADO
}

\author{
Alexandre Campane Vidal, Sérgio Sacani Sancevero, Armando Zaupa Remacre \\ e Caetano Pontes Costanzo \\ Recebido em 5 julho, 2007 / Aceito em 27 setembro, 2007 \\ Received on July 5, 2007 / Accepted on September 27, 2007
}

\begin{abstract}
The aim of this work is analyze the vertical seismic resolution of the turbidity reservoir of Namorado Field. In this work the seismic modeling was accomplished using the convolution method. The wavelet used was the Ricker type with dominant frequency of $20 \mathrm{hz}, 35 \mathrm{hz}$ and $50 \mathrm{hz}$. The results show that wavelet with frequencies of $35 \mathrm{hz}$ and $50 \mathrm{hz}$ have better seismic resolution than wavelets of $20 \mathrm{hz}$, however all frequencies delimit top and base of the reservoir. From the acoustic impedance model, obtained from the synthetic seismogram, was possible, knowing the correlation of this variable with reservoir rocks, determine the distribution of reservoir facies. For that was used the geostatistical analysis that still enabled the studies regarding to the scenarios analysis by means of the application of stochastic methods.
\end{abstract}

Keywords: seismic modeling, acoustic impedance, geostatistic.

RESUMO. Este trabalho avalia a resolução sísmica vertical do reservatório turbidítico do Campo de Namorado, por meio da modelagem sísmica 1D utilizando 0 método da convolução. A wavelet escolhida foi a do tipo Ricker com freqüências de $20 \mathrm{hz}, 35 \mathrm{hz}$ e $50 \mathrm{hz}$. Os resultados obtidos determinam que as wavelets com freqüências de $35 \mathrm{hz}$ e $50 \mathrm{hz}$ apresentaram melhor resolução sísmica quando comparadas com as wavelets de $20 \mathrm{hz}$, porém todas as freqüências delimitaram topo e base do reservatório e em alguns poços foi possível identificar heterogeneidades internas. A partir do modelo de impedância acústica, obtido para a geração do sismograma sintético, foi possível, conhecendo a correlação dessa variável com as litologias do campo, determinar o modelo tridimensional da fácies reservatório. Para isso foi utilizada a análise geoestatística que possibilitou ainda a geração de cenários otimistas e pessimistas por meio da aplicação de métodos estocásticos.

Palavras-chave: modelagem sísmica, impedância acústica, geoestatística. 


\section{INTRODUÇÃo}

0 método sísmico é amplamente utilizado em estudos de reservatórios, com o objetivo de gerar mapas de variáveis que forneçam um significado geológico, ou seja, que possam ser relacionados com a profundidade das estruturas e das propriedades petrofísicas que constituem o reservatório (Sheriff \& Geldart, 1995).

Porém, mesmo sendo adquirido e processado de maneira correta, o dado sísmico fornece apenas uma imagem aproximada das estruturas em subsuperfície. Desse modo, relacionar o dado sísmico com as informações de poço é uma tarefa importante para auxiliar no processo de interpretação geológica.

Assim, a geração de sismogramas sintéticos 1D, a partir de informações de poços, ou mesmo de afloramentos, possibilita a simulação das possibilidades de configurações sísmicas para diversos problemas geológicos. Isso é possível ao transformar um perfil das propriedades de rocha em traços sísmicos sintéticos Mesmo para reservatórios contendo linhas sísmicas, a realização de sismogramas sintéticos é fundamental como ferramenta auxiliar do intérprete na integração sísmica-poço.

Para a geração da sísmica sintética 1D, foi utilizada a modelagem convolucional, que considera o traço sísmico como a convolução entre a wavelet e a série de coeficientes de reflexão (Sheriff \& Geldart, 1995). Dentre as variáveis associadas à modelagem convolucional, a freqüência dominante da wavelet é importante por definir o poder de resolução da informação sísmica.

0 processo de geração de sísmica sintética, a partir de dados de poços, permite, pela utilização dos perfis densidade e sônico, o cálculo da impedância acústica. Além de contribuir como ligação entre os dados sísmicos e de poços, a variável impedância acústica é originaria do produto da densidade da rocha e velocidade da onda $\mathrm{P}$, com isso é uma propriedade da rocha e não de interface entre litologias (Latimer et al., 2000).

Neste trabalho, foi realizada a geração da sísmica sintética $1 \mathrm{D}$ para as freqüências dominantes de wavelets de 20 hz, $35 \mathrm{hz}$ e 50 hz. Além disso, foi gerada a variável impedância acústica, por meio de perfis de poços, e realizada a interpolação 3D dessa variável.

A base de dados utilizada refere-se às informações do Campo de Namorado, disponibilizada pela Agência Nacional do Petróleo, Gás Natural e Biocombustíveis (Fig. 1). De uso comum em pesquisas na área de petróleo, a base de dados apresenta apenas algumas linhas sísmicas posicionadas nas bordas do campo. A aplicação do método de geração de dados sísmicos, a partir de poços, pode auxiliar na definição da resposta sísmica e distribuição da variável impedância acústica ao longo do campo.

\section{MÉTODO}

A impedância acústica $(I)$ de um meio elástico é a razão da tensão pela velocidade de propagação das partículas, obtida pelo produto entre a densidade de rocha $(\rho)$ e a velocidade compressional de propagação da onda $(V)$. Na interface plana entre dois meios elásticos, espessos, homogêneos e isotrópicos, a refletividade de incidência normal para ondas viajando de um meio para outro, é a razão do deslocamento da amplitude $A_{r}$ da onda refletida pelo deslocamento de amplitude da onda incidente $A_{i}$, sendo definida pela seguinte equação:

$$
R_{12}=\frac{A_{r}}{A_{i}}=\frac{I_{2}-I_{1}}{I_{2}+I_{1}}=\frac{\rho_{2} V_{2}-\rho_{1} V_{1}}{\rho_{2} V_{2}+\rho_{1} V_{1}}
$$

onde $I$ representa a impedância acústica, $R$ é 0 coeficiente de reflexão, os índices 1 e 2 são respectivamente os meios superior de propagação da onda e inferior, na direção de transmissão da onda.

Na equação 1, o coeficiente de reflexão é obtido quando 0 deslocamento da partícula é medido com relação à direção de propagação da onda. Um deslocamento é positivo quando seu componente ao longo da interface tem a mesma fase, ou a mesma direção do componente do vetor da onda ao longo da interface. Para ondas compressionais, isso significa que um deslocamento positivo é ao longo da direção de propagação. Desse modo, um coeficiente de reflexão positivo implica na compressão e a fase do sinal é a mesma do sinal original gerado pela fonte sísmica, no caso de um coeficiente de reflexão negativo implica na inversão de fase (Mavko et al., 1998).

A refletividade é o conceito físico fundamental para compreensão das informações sísmica, cada coeficiente de reflexão pode ser avaliado como a resposta do sinal sísmico pela mudança na impedância acústica (Russell, 1991). Ao considerar que a refletividade consiste no coeficiente de reflexão em cada amostragem temporal, e a wavelet é uma função suavizadora no tempo, o processo de convolução (representado pelo símbolo $*$ ) pode ser descrito como a troca de cada coeficiente de reflexão $(r)$ por uma versão escalonada da wavelet $(w)$. De acordo com Russell (1991), o traço sísmico $(S)$ é obtido através da convolução entre a wavelet e a refletividade com a adição de um ruído ( $n$ ) (Eq. 2).

$$
S(t)=w(t) * r(t)+n(t)
$$

Para a geração do traço sísmico, foi determinada a impedância acústica a partir de 14 poços, em formato $L A S$, contendo os perfis geofísicos de GR (raio gama), DT (sônico), ILD (resistividade), NPHI (porosidade neutrão) e RHOB (densidade). A fase inicial desse trabalho foi destinada à organização dos dados do 


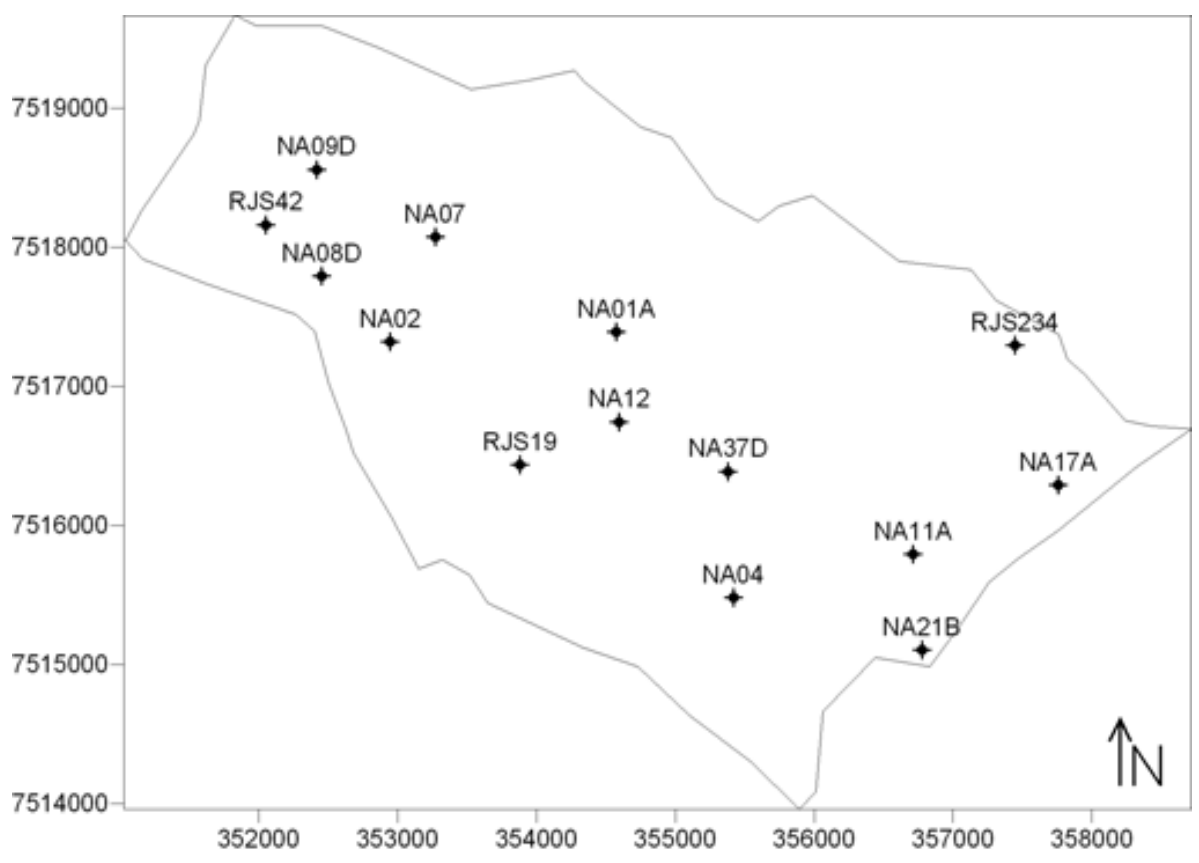

Figura 1 - Mapa do Campo de Namorado com a localização dos poços utilizados neste trabalho.

Campo de Namorado. Todo o processamento dos dados foi realizado com o desenvolvimento de rotinas de programação para ajustar os dados ao formato de entrada dos softwares utilizados.

0 critério para a seleção dos poços foi o registro contínuo dos perfis densidade (RHOB) e sônico (DT), que são necessários para a geração da variável impedância acústica. Os valores do perfil sônico são dados em vagarosidade que é o inverso da velocidade. A impedância acústica é o resultado da multiplicação do inverso dos valores do perfil sônico (Vp) pelos valores de densidade (RHOB), como mostra a equação 3 :

$$
\mathrm{IA}=\mathrm{RHOB} \times \mathrm{Vp} .
$$

Os dados sísmicos e a wavelet são adquiridos em tempo, por outro lado os perfis de poços são referenciados em profundidade. Por isso, para a junção dos dados em profundidade para tempo, é necessária a aplicação da lei de conversão, baseada na variação da velocidade com a profundidade, utilizando perfis de velocidade ou sônico. Assim os dados são transformados para 0 domínio do tempo.

A regularização dos dados foi executada com o objetivo de reduzir o efeito de suporte e gerar dados que possuam consistência sísmica e geológica. 0 algoritmo envolvido na regularização dos dados de impedância acústica consiste em aplicar conceitos de freqüência de Nyquist para filtrar a informação e então re-amostrar em intervalos de $4 \mathrm{~ms}$.
Para a geração do traço sísmico foi aplicada a equação 2, sendo a componente ruído considerada nula. Isso foi definido para enfatizar as variações relacionadas à mudança na frequêencia dominante da wavelet nas intercalações litológicas observadas na escala de reservatório. A adoção do ruído acrescentaria uma variável que não será alvo de pesquisa nesta análise.

A wavelet escolhida foi a do tipo Ricker, sendo utilizadas as freqüências dominantes de 20 hz, 35 hz e 50 hz. Para auxiliar na interpretação dos resultados, foram criados gráficos que apresentam a junção entre o traço sísmico gerado e os perfis de GR e RHOB. Esta junção tem a finalidade de auxiliar na análise das características geológicas do reservatório e avaliar a resposta da variação litológica no traço sísmico. A utilização dos perfis GR e RHOB são suficientes para identificar as principais características internas do reservatório (Souza Junior, 1997).

A geoestatística foi aplicada para a elaboração do modelo geológico 3D da variável impedância acústica. Para isso, foi utilizada a krigagem ordinária, que estima o valor em um ponto ou região, onde o variograma é conhecido, utilizando-se os dados da vizinhança, por meio de combinação linear dos ponderadores (Wackernagel, 1995).

A segunda etapa da análise geoestatística foi destinada à modelagem estocástica. A Simulação Seqüencial Gaussiana, aplicada em variáveis contínuas, foi utilizada para a análise da variável impedância acústica. 
0 método de Simulação Seqüencial Gaussiana tem sido largamente utilizado para 0 estudo de reservatórios de petróleo (Journel \& Alabert, 1989; Deutsch, 2002). Neste algoritmo, 0 valor simulado para cada ponto da malha é obtido somando-se ao valor krigado um resíduo, que é obtido aleatoriamente de uma função de distribuição normal com média e variância igual à da krigagem simples. A Simulação Seqüencial Gaussiana pode ser condicional ou não condicional. No primeiro caso, os dados presentes na área são considerados, e ao final da simulação 0 desvio padrão nesses pontos é nulo.

No algoritmo da Simulação Seqüencial Gaussiana (SSG), cada variável é simulada, de acordo com a sua função de distribuição gaussiana, por meio do sistema de krigagem (Oliveira, 1997). A cada etapa, os dados condicionantes são todos os valores originais somados aos valores previamente simulados que se encontram dentro de uma vizinhança da posição a ser simulada.

0 algoritmo utilizado para a execução da SSG apresenta as seguintes etapas: (a) Realização da transformação da variável para uma distribuição gaussiana (anamorfose); (b) Análise variográfica da variável para escolha do modelo; (c) Definição da vizinhança; (d) Efetivação da simulação; (e) transformação inversa da variável gaussiana para os valores do atributo em estudo.

Todo o processamento dos dados foi executado com auxílio dos softwares EasyTrace 4.0 (1999), para a geração do sismograma sintético, e, para o trabalho envolvendo a geoestatística, 0 software Isatis 6.04 (Bleines et al., 2000).

\section{CAMPO DE NAMORADO}

Descoberto em 1975, o Campo de Namorado está localizado na parte centro-norte da zona de acumulações de hidrocarbonetos da Bacia de Campos, a 80 km da costa, em profundidade d'água entre $140 \mathrm{~m}$ e $250 \mathrm{~m}$. 0 reservatório é constituído por arenitos turbidíticos Namorado, de idade Albiano superior a Cenomaniano médio/superior.

0 Campo de Namorado está inserido na seção de calcilutitos, margas e folhelhos da Formação Macaé, membros Outeiro e Quissamã. 0 reservatório está posicionado em estrutura alongada de direção NW-SE, associado a depósitos em canais e em lobos, intercalados por sedimento hemipelágicos.

As informações obtidas da descrição seqüencial de testemunho evidenciam a complexidade geológica desse reservatório, que é composto pela predominância de arenitos e folhelhos e, secundariamente, por conglomerados, brechas, siltitos e margas. De acordo com as descrições de testemunho, são observadas, no total, 23 fácies litológicas.
As principais rochas reservatórios descritas são referentes a duas fácies de arenitos, que apresentam espessuras métricas nos testemunhos. A fácies de maior ocorrência nos testemunhos corresponde a fácies arenito médio maciço, arcoseano e bem selecionado. A segunda fácies são arenitos grossos amalgamados, com gradação da fração areia grossa-conglomerática na base para fração grossa no topo.

0 reservatório é limitado por fechamentos estratigráficos e estruturais, que delimitam o campo à área aproximada de $21 \mathrm{~km}^{2}$. Os limites de topo e base do sistema turbidítico Namorado são claramente reconhecidos por perfis geofísicos. 0 limite inferior é identificado a partir dos contrastes de densidade (RHOB) e radiotividade (GR) entre os turbiditos e os cabonatos da base. 0 topo é bem marcado em perfis raios gama pela forte radioatividade das argilas posicionadas no topo do reservatório (marco radioativo).

Em relação às seções sísmicas, a base do reservatório é facilmente identificável devido ao forte contraste de impedância entre os arenitos turbidíticos e os carbonatos. Entretanto, para o topo do reservatório, a incerteza é maior devido à ausência de contraste de impedância significativo entre os folhelhos do topo e as intercalações de arenito e folhelho do reservatório.

A estratigrafia interna do reservatório pode ser claramente identificada por meio da geração da curva de proporção vertical, que retrata a proporção de cada fácies entre os poços, em níveis paralelos a um referencial adotado (Souza Junior, 1997; Johann, 2004).

Esta análise utilizou o marco radioativo do topo como horizonte de referência. Os resultados apontaram três ciclos, com arenitos na base e finos no topo, sendo possível de ser observado por meio dos perfis raios gama. A clara identificação desses ciclos é possível na porção central do campo, enquanto na porção marginal ocorre alta incerteza na identificação dos ciclos (Souza Junior, 1997). A identificação desses ciclos foi realizada por Johann (1997), que utilizou dados sísmicos com a geração do cubo de coeficientes de reflexão associados à interpretação de unidades sismo-estratigráficas.

Johann (2004) adota a divisão do reservatório em três seqüências, e por meio da análise multivariada e ferramentas geoestatísticas, realiza um estudo detalhado de fácies sísmicas do Campo de Namorado.

\section{RESULTADOS E DISCUSSÃO \\ Análise 1D - Geração de sísmica sintética}

A sísmica sintética foi gerada para todos os poços, aplicando as frequiências dominantes de 20 hz, 35 hz e 50 hz. 0 resultado obtido é representado na forma gráfica juntamente com os perfis 
raios gama e densidade, além da indicação de topo e base do reservatório (Fig. 2).

Os resultados comprovaram que, na maioria dos poços, a base do reservatório pode ser identificada para as freqüências utilizadas, como exemplo o poço NA12. Em poucos poços ocorre a definiç̧ão da base, com inversão na polaridade. A exceção para a boa definição do limite basal pode ser representada pelo poço RJS234, que está posicionado na borda do campo, em situação de pouca espessura de reservatório. Nesse poço pode-se observar 0 deslocamento do pico referente à base, para as diferentes freqüências.

A definição do topo do reservatório ocorre pela transição entre os folhelhos da Fm. Macaé e os arenitos do Campo de Namorado. Diferente da resposta sísmica para a base do reservatório, a sísmica obtida para o topo apresenta menor definição na maioria dos poços estudados.

Ao observar o padrão dos perfis, em alguns poços, constatase que na região do topo do reservatório ocorrem intercalações delgadas entre folhelhos e arenitos até atingir os intervalos espessos de rocha-reservatório, em outros casos o marco radioativo é destacado na sísmica, poços NA02 e NA07. Porém a definição do topo pode ser constatada no poço NA12 e NA09.

A melhor resolução vertical para as heterogeneidades internas foi determinada pelas freqüências de 35 e $50 \mathrm{hz}$, em que é possível definir espessos intervalos litológicos. Como esperado, para a freqüência de $20 \mathrm{hz}$ foram obtidas menores resoluções, entretanto, para alguns poços, esta freqüência foi suficiente para delimitar topo e base do reservatório.

Os resultados da resposta da sísmica para as heterogeneidades internas do reservatório são distintos para cada poço, constatado pelo padrão diferenciado do comportamento dos perfis raios gama e densidade. Nesse caso, é verificado que nas porções centrais do campo, onde a espessura do reservatório é maior, a sísmica com freqüências mais altas é capaz de determinar as variações litológicas. Entretanto, como esperado, em direção às bordas do campo, em menores espessuras de reservatório, ocorre pouca definição das heterogeneidades.

A sísmica sintética delimita internamente duas a três seqüências para o reservatório de Namorado, quando utilizadas as wavelets com freqüências dominantes de 35 e $50 \mathrm{hz}$. Em alguns casos, como no poço NA12, o perfil densidade delimita espessos pacotes de rocha reservatório e não-reservatório, o que favoreceu a identificação destas intercalações na sísmica. Nos poços em que as intercalações entre folhelhos e arenitos ocorrem em menores espessuras, as wavelets com freqüência dominante de 35 e $50 \mathrm{hz}$ apresentam respostas distintas (NA37 e NA9).

\section{Análise 3D - Variável Impedância Acústica}

A análise da variável Impedância Acústica foi realizada para os mesmos poços utilizados na geração do traço sísmico. Para essa etapa foi definido apenas 0 intervalo do poço referente ao reservatório, com acréscimo na janela de $50 \mathrm{~m}$ e $150 \mathrm{~m}$, respectivamente ao limite do topo e a base do campo.

A etapa inicial da análise da impedância acústica foi a caracterização desse atributo por meio da análise estatística. Os valores dessa variável apresentam mínimo de $5.771 \mathrm{~m} / \mathrm{s} . \mathrm{gr} / \mathrm{cm}^{3}$ e máximo de $15.137 \mathrm{~m} / \mathrm{s} . \mathrm{gr} / \mathrm{cm}^{3}$, com média de $9.610 \mathrm{~m} / \mathrm{s} . \mathrm{gr} / \mathrm{cm}^{3}$ e desvio padrão de 1.878. A distribuição desses valores permite constatar o comportamento bimodal claramente definido (Fig. 3A).

A avaliação da distribuição bimodal permite inferir aos dados um limite $10.000 \mathrm{~m} / \mathrm{s} . \mathrm{gr} / \mathrm{cm}^{3}$ para a separação entre os dois grupos, conforme mostrado na Figura 3A. A localização desses valores nos poços permite apontar que os valores mais baixos de impedância estão situados na porção superior, enquanto os maiores nas porções basais dos poços, esta distribuição é apresentada na Figura 3B.

Essa bimodalidade é atribuída a variação litológica do intervalo em estudo. Por meio de correlação dos valores de impedância com as litologias definidas para os poços, foi possível identificar que os carbonatos apresentam valores superiores a $11.000 \mathrm{~m} / \mathrm{s} . \mathrm{gr} / \mathrm{cm}^{3}$. Valores próximos a $10.000 \mathrm{~m} / \mathrm{s} . \mathrm{gr} / \mathrm{cm}^{3} \mathrm{se}-$ riam referentes, principalmente, às margas e folhelhos.

Os valores inferiores a $10.000 \mathrm{~m} / \mathrm{s} . \mathrm{gr} / \mathrm{cm}^{3}$ seriam representados pelas litologias contidas no reservatório constituídos, em sua maioria, por arenitos e folhelhos, e pelos folhelhos posicionados na porção superior do campo. Neste grupo, os valores inferiores a $8.000 \mathrm{~m} / \mathrm{s} . \mathrm{gr} / \mathrm{cm}^{3}$ são referentes aos arenitos.

A interpolação dos dados de impedância foi realizada por meio da krigagem ordinária 3D. Para isso, as informações dos poços foram regularizadas para $1 \mathrm{~m}$ e 0 topo do reservatório foi rebatido para mesma cota altimétrica. Com os dados posicionados em nova cota, o mapa da base do campo foi utilizado para orientar na interpretação da interpolação e extrapolação da impedância.

A modelagem do variograma em duas direções definiu alcance próximo a 1.500 nas direções horizontais. Embora com pequeno número de poços, o valor de alcance nos variogramas, indica que não há diferenças na continuidade dos arenitos na direção NW-SE como no variograma ortogonal a essa direção.

No variograma referente à direção vertical, foi observado um comportamento de deriva. A não-estacionaridade é reflexo do aumento contínuo dos valores de impedância com 0 aumento da 

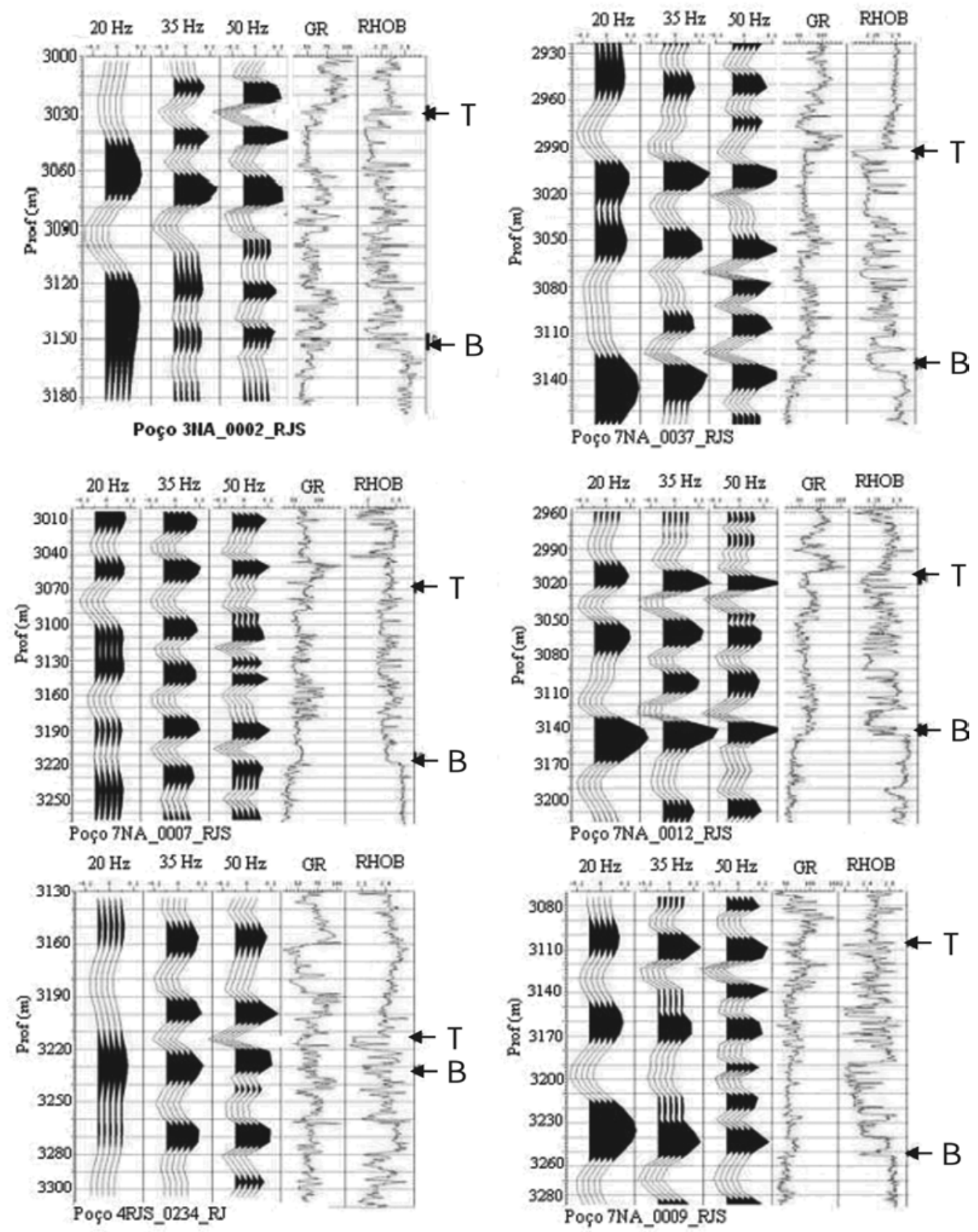

Figura 2 - Sismogramas sintéticos de 6 poços com diferentes freqüências dominantes de wavelets e os perfis raios gama (GR) e densidade (RHOB). 0 topo e a base do reservatório estão indicados por T e B, respectivamente.

profundidade, fato que se deve à maior presença de carbonatos na base do campo.

A partir do modelo gerado por meio da krigagem, foi possível identificar determinadas feições importantes para a caracterização do reservatório do Campo de Namorado. A principal característica está relacionada aos três ciclos sedimentares (Fig. 4).
Marcados pelos baixos valores de impedância, pode-se observar a disposição das rochas reservatório em três intervalos compreendidos no campo. No topo pode ser identificada camada contínua de baixo valor de impedância e que corresponde ao principal intervalo portador de hidrocarbonetos. As camadas reservatórios inferiores apresentam continuidade menos pronunciada. 

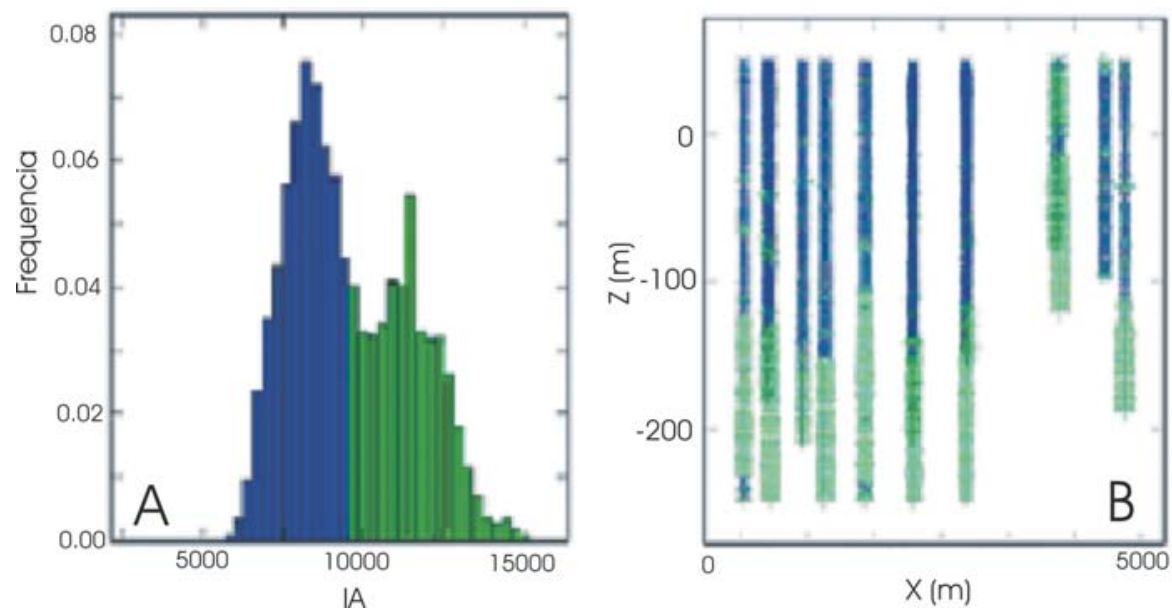

Figura 3 - Distribuição dos valores de impedância acústica. A cor azul é para os valores inferiores a $10.000 \mathrm{~m} / \mathrm{s} . \mathrm{gr} / \mathrm{cm}^{3}$ e a cor verde para os valores superiores. (A) Valores de impedância acústica plotados ao longo de alguns poços, mostrando 0 predomínio de baixos valores na porção superior. (B) Histograma dos valores de impedância mostrando a distribuição bimodal.

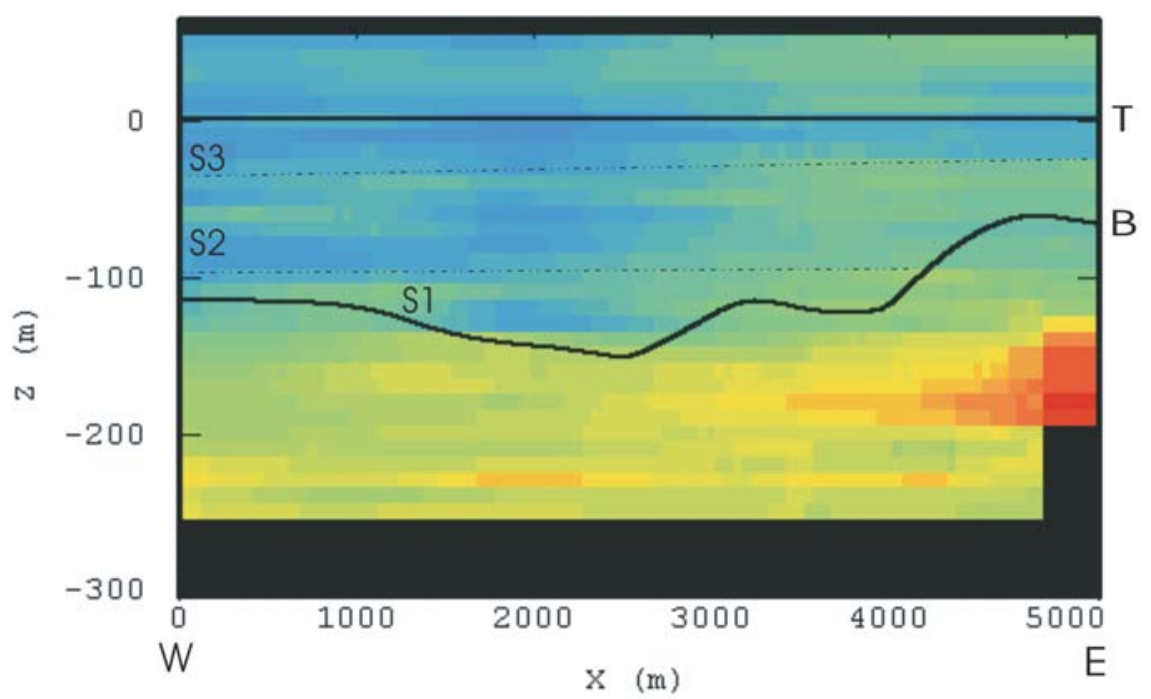

Figura 4 - Seção E-W da distribuição dos valores de impedância acústica. A linha posicionada na profundidade de valor zero representa o topo do reservatório (T). A linha inferior representa a base do reservatório inserida na figura com objetivo de fornecer os limites do reservatório (B). As linhas tracejadas S1, S2 e S3 representam as seqüências de deposição no reservatório.

A dificuldade para a identificação do topo do reservatório nos traços sísmicos gerados pode ser confirmada na porção oeste, que evidencia os baixos valores de impedância posicionados acima do topo do reservatório (Fig. 4).

Como esperado, os maiores valores de impedância estão posicionados na base, no entanto há o incremento nesses valores em direção a leste, resultado da predominância de carbonatos nessa porção.

A caracterização do reservatório foi baseada apenas por 14 dados de poços, por isso foi realizada a Simulação Seqüencial Gaussiana da variável impedância acústica, com 0 objetivo de melhorar a caracterização das heterogeneidades e incorporar a incerteza associada na estimativa, pois a krigagem ordinária fornece apenas uma solução e suaviza as heterogeneidades do modelo gerado.

Uma das vantagens de realizar a simulação estocástica consiste na possibilidade de gerar cenários equiprováveis da variável estudada, esses cenários podem ser utilizados na análise de in- 
certeza do volume de óleo para o campo ou serem inseridos no processo de simulação de fluxo de modo a se testar o desempenho do campo em diferentes situações.

Ao invés de analisar as diversas realizações individualmente, os resultados são classificados conforme o somatório dos maiores valores de impedância para os modelos, com isso é possível adotar para análise cenários probabilísticos para a impedância acústica. Neste trabalho 3 cenários foram gerados referentes a P10 (pessimista), P50 (mais provável) e P90 (otimista) (Fig. 5).

0 cenário considerado otimista apresenta regiões referentes aos valores de alta e baixa impedância acústica bem definidas. Neste caso, como era de se esperar a alta probabilidade da ocorrência de folhelhos e margas na porção leste inferior, bem como uma alta probabilidade da ocorrência de arenitos na porção oeste superior, sendo que a base do reservatório apresenta alta probabilidade de ocorrência de rochas como folhelhos e margas.

0 cenário referente a P50 representa a situação mais provável de ocorrer no reservatório. Observa-se claramente que as regiões constituídas de rochas distintas ficam bem marcadas no modelo, atribuindo assim maior confiança as interpretações.

Por fim, no cenário pessimista P10 observa-se mais uma vez a clara divisão entre os tipos de rochas distintos que formam 0 reservatório de Namorado. Esse cenário é dito pessimista pelo fato dos valores elevados de impedância, ou seja, rochas nãoreservatório apresentam maior extensão, principalmente intercalados com os arenitos do reservatório. Ao comparar com os outros cenários apresentados pode-se inferir o impacto desses diferentes cenários no volume de óleo e comportamento do fluxo no reservatório.

Em todos os modelos gerados é possível observar a menor espessura e baixa qualidade da rocha reservatório na porção leste. Esta porção corresponde ao bloco baixo do campo, compartimentado por falha de direção N-S, posicionada no topo do modelo pela etapa de deslocamento do topo para mesma cota.

Embora não utilizada na interpolação, a falha pode ser inferida pelo contraste dos valores de impedância no reservatório e pelo posicionamento de carbonatos (alto valor de impedância) ao lado do reservatório a oeste.

Outra análise dos resultados da simulação estocástica corresponde à análise de valores de cortes, com o objetivo de estudar a probabilidade de se encontrar, no reservatório, regiões acima ou abaixo de um determinado valor da variável estudada. Neste caso, estabeleceu-se um valor de corte igual a $10.000 \mathrm{~m} / \mathrm{s} . \mathrm{gr} / \mathrm{cm}^{3}$, considerado o limite da impedância acústica para 0 arenito. Com isso calculou-se um modelo que mostra a probabilidade de se encontrar valores abaixo de $10.000 \mathrm{~m} / \mathrm{s} . \mathrm{gr} / \mathrm{cm}^{3}$ (Fig. 6).
A análise desse modelo, juntamente com os demais resultados apresentados, pode então fornecer uma idéia geral de onde estão os principais alvos exploratórios, reduzindo assim o risco na sua exploração.

0 modelo apresentado na Figura 6 confirma as demais interpretações mencionadas anteriormente. Nota-se que na porção superior oeste do reservatório existe maior probabilidade, superior a $60 \%$, de se encontrar valores de impedância abaixo de $10.000 \mathrm{~m} / \mathrm{s} . \mathrm{gr} / \mathrm{cm}^{3}$, ou seja, referentes a reservatórios. Já na porção basal e na porção leste inferior, a probabilidade de se encontrar tal situação é reduzida em média para 30\% ou menos.

Por meio dos resultados gerados pela simulação estocástica foi possível apresentar a gama dos possíveis cenários para 0 campo. Os destaques para a utilização desse método são a geração de modelos que reproduzem de forma mais consistente as heterogeneidades presentes no reservatório, não gerando resultados suavizados como no caso da krigagem e a possibilidade de gerar diversos modelos que podem ser estudados sobre 0 aspecto da incerteza visando reduzir o risco exploratório e fornecendo subsídios para que a simulação de fluxo possa estudar diferentes desempenhos do mesmo reservatório.

Apesar da utilização de apenas 14 poços, das limitações na utilização da análise $1 \mathrm{D}$ para a geração do traço sísmico e da aplicação dos valores de impedância acústica provenientes de dados de poços, os resultados obtidos são compatíveis com os trabalhos realizados para o Campo de Namorado (Souza Junior, 1997; Johann, 2004). Esses trabalhos utilizaram maior número de poços, além de linhas sísmicas.

\section{CONCLUSÃO}

Os resultados evidenciam a grande utilidade desse método para auxiliar no processo de interpretação sísmica do reservatório e para o estudo da assinatura sísmica de intervalos geológicos.

Os resultados obtidos para o Campo de Namorado comprovam que as wavelets com freqüências dominantes intermediárias, ou seja, 35 e 50 hz, apresentam a melhor resolução com a definição das principais heterogeneidades internas. A wavelet com freqüência de 20 hz mostrou-se útil apenas para a delimitação de topo e base do reservatório, o que ocorre em situações reais de aquisição sísmica.

A interpolação e extrapolação dos dados de impedância acústica mostraram ser eficiente para definir as heterogeneidades do Campo de Namorado. A malha gerada apresentou claramente os três ciclos sedimentares na porção central do campo. Além disso, os valores interpolados mostraram diferenças para as definições 

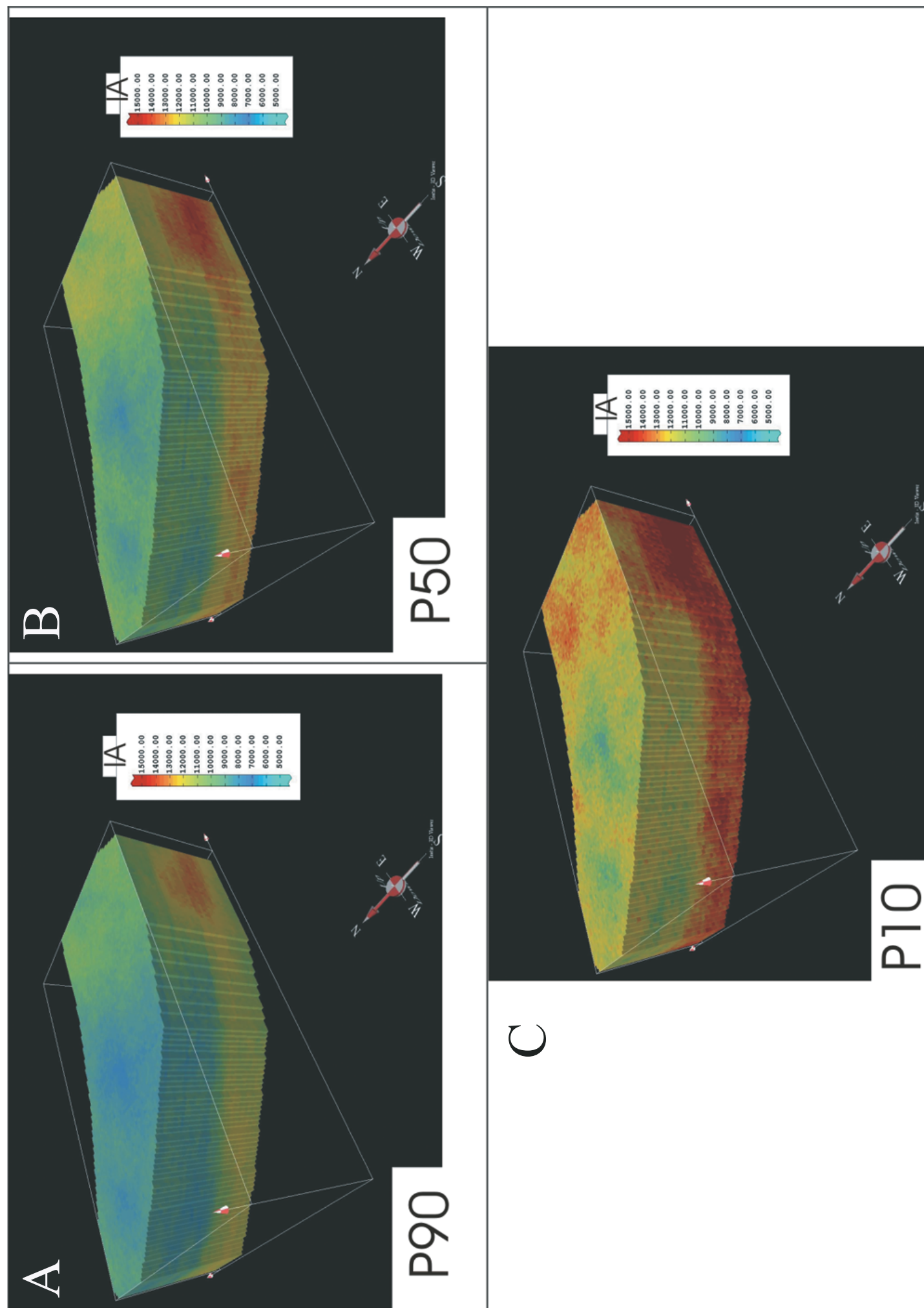

Figura 5 - Resultados da simulação estocástica da variável impedância acústica. A - o cenário otimista (P90), B - 0 cenário mais provável (P50) e $\mathrm{C}-0$ cenário pessimista (P10). 


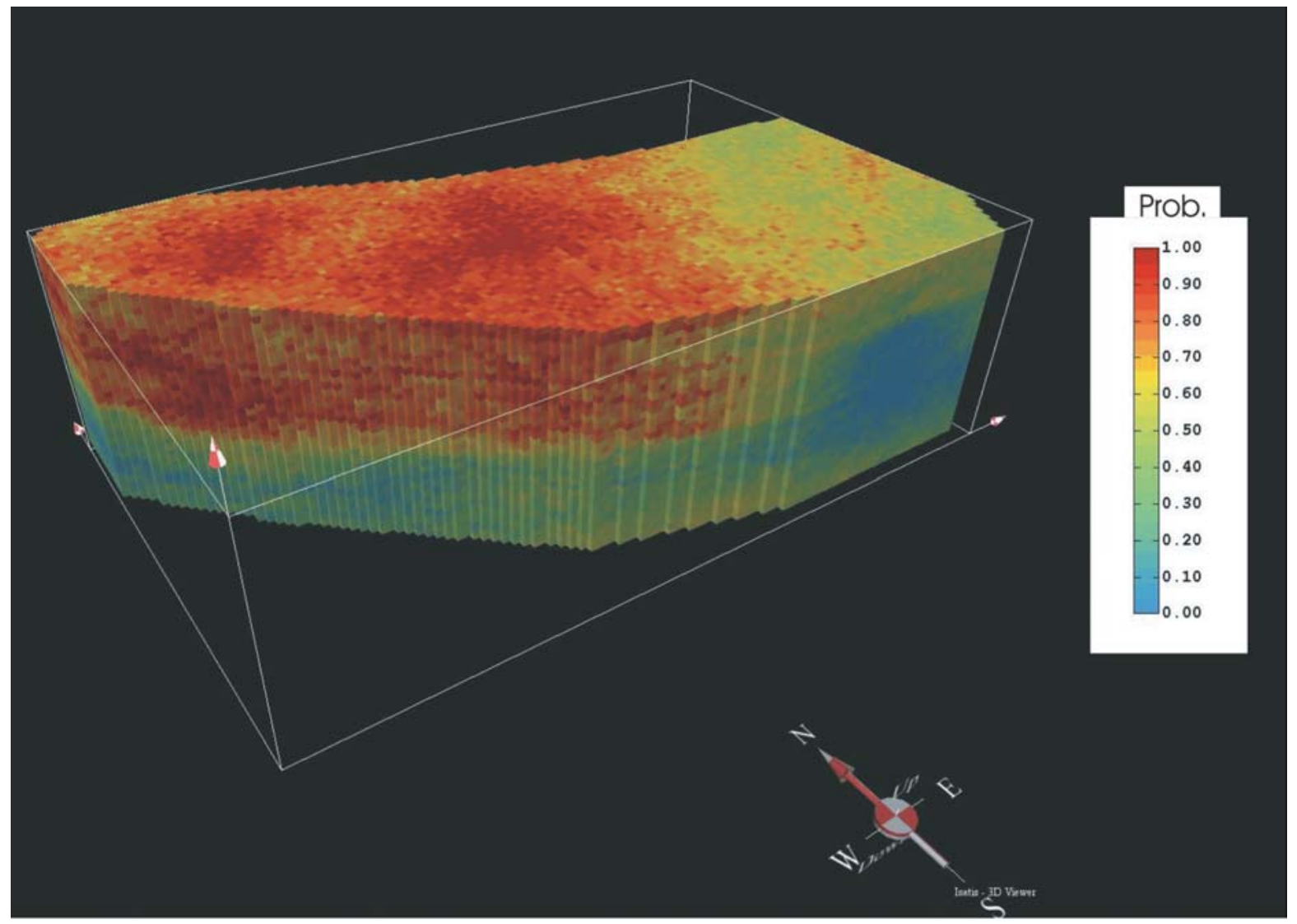

Figura 6 - Modelo de probabilidade de ocorrência de valores de impedância acústica inferiores a $10.0000 \mathrm{~m} / \mathrm{s.gr} / \mathrm{cm}^{3}$.

de base, com transição bem definida, e topo com uma transição menos marcante.

\section{AGRADECIMENTOS}

Agradecemos à ANP (Agência Nacional do Petróleo, Gás Natural e Biocombustíveis) por fornecer os dados necessários para este trabalho e à Beicip-Franlab pelo suporte para a utilização do Software EasyTrace.

\section{REFERÊNCIAS}

BLEINES C, PERSEVAL S, RAMBERT F, RENARD D \& TOUFFAIT Y. 2000. ISATIS Software Manual. Geovariances \& École des Mines de Paris. $585 \mathrm{pp}$.

DEUTSCH CV. 2002. Geostatistical Reservoir Modeling. Applied Geostatistics Series, Oxford University Press. 400 pp.

EASYTRACE. 1999. Advanced Log Processing and Editing (Version 4.0). IFP - Beicip-Franlab. 308 pp.

JOHANN PRS. 1997. Inversion Sismostratigraphique et Simulations Sto- chastiques en 3D: Réservoir Turbiditique Offshore du Brésil, Intégration Géologique, Géophysique et Géostatistique, Ph.D. Thesis, Académie de Paris, Université Marie Curie. 352 pp.

JOHANN PRS. 2004. Fácies Sísmicas. Boletim Geociências Petrobras, 12(12): 317-355.

JOURNEL AG \& ALABERT F. 1989. Non-Gaussian data expansion in the Earth Sciences. Terra Nova, 1: 123-134.

LATIMER RB, DAVISON R \& RIEL PV. 2000. An Interpreter's guide to understanding and working with seismic - derived acoustic impedance data. The Leading Edge, 242-254.

MAVKO G, MUKERJI T \& DVORKIN J. 1998. The Rock Physics Handbook, Cambridge University Press. 339 pp.

OLIVEIRA ML. 1997. Análise das incertezas envolvidas na modelagem de reservatório no contexto geoestatístico. Campinas: Faculdade de Engenharia Mecânica/Instituto de Geociências, Universidade Estadual de Campinas. Dissertação (Mestrado). 115 pp.

RUSSELL BH. 1991. Introduction to Seismic Inversion Methods. S. N. Domenico, 2: 129 pp. 
SHERIFF RE \& GELDART LP. 1995. Exploration seismology: Cambridge, Cambridge University Press. 575 pp.

SOUZA JUNIOR OG. 1997. Stratigraphie Séquentielle et Modélisation Probabiliste des Réservoirs d'un Cône Sous-marin Profond (Champ de
Namorado, Brésil). Intégration des Données Géologiques. Thése de Doctorat. Université Paris. 128 pp.

WACKERNAGEL H. 1995. Multivariate geostatistics: an introduction with applications. Springer, 256 pp.

\section{NOTAS SOBRE OS AUTORES}

Alexandre Campane Vidal é formado em Geologia pela Universidade de São Paulo em 1993, obteve o título de mestre em Geoengenharia de Reservatórios pela Universidade Estadual de Campinas, em 1997, e doutorado em Geologia Regional pela UNESP, em 2003. Durante o período de 2002-2003 fez pós-doutorado no departamento de Geologia Aplicada pela Universidade Estadual Paulista. Atualmente é Professor Assistente Doutor do Departamento de Geologia e Recursos Naturais do Instituto de Geociências da Universidade Estadual de Campinas. Tem experiência na área de Geologia, com ênfase em Geologia de Reservatórios.

Sérgio Sacani Sancevero é formado em Geofísica pela Universidade de São Paulo em 2000, no mesmo ano ingressou na indústria de petróleo trabalhando como observer em empresa de aquisição sísmica em trabalhos na costa brasileira. Em 2001 ingressou no mestrado em Engenharia de Petróleo na Universidade Estadual de Campinas. Participou de um projeto pertencente ao programa PRAVAP/19 na área de inversão sísmica. Suas áreas de atuação incluem, modelagem de reservatório, inversão sísmica e geoestatística.

Armando Zaupa Remacre recebeu seu Ph.D. em geoestatística na École de Mines de Paris em 1984. De 1984 a 1988 trabalhou como professor assistente de geoestatística na Universidade Federal de Ouro Preto. Em 1988 transferiu-se para a UNICAMP, para o Departamento de Geologia e Recursos Naturais. Suas principais atividades de pesquisa incluem a aplicação de técnicas geoestatísticas na caracterização de reservatórios, como a modelagem das heterogeneidades, integração de dados (perfis de poços, sísmica e afloramentos), modelagem estocástica, análise de incertezas e tomada de decisão. Também desenvolve projetos com aplicações na mineração e meio ambiente.

Caetano Pontes Costanzo é aluno do curso de Geologia da Universidade Estadual de Campinas. Em 2005 ingressou na área de Geologia de Recursos Petrolíferos, por meio da bolsa de iniciação científica PRH-ANP 15 (Ciências e Engenharia dos Recursos Naturais de Óleo e Gás). Atualmente desenvolve trabalhos na área de modelagem sísmica aplicada a reservatório. 